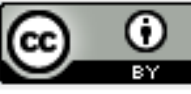

\title{
PROPOSTA DE MÉTODO PARA A FORMULAÇÃO DE ESTRATÉGIA EM PEQUENAS E MÉDIAS EMPRESAS
}

\section{PROPOSAL OF A METHOD FOR FORMULATING STRATEGY IN SMALL AND MEDIUM ENTERPRISES}

\author{
Luís Henrique Piovezan \\ Professor \\ SENAI-SP \\ Escola SENAI “Orlando Laviero Ferraiuolo” \\ Rua Teixeira de Melo, 106 Tatuapé - CEP 03067-000 - São Paulo - SP \\ (11)6191-5801 r. 219 - apescolar111@sp.senai.br
}

Fernando José Barbin Laurindo

Professor Associado

Escola Politécnica da Universidade de São Paulo

Departamento de Engenharia de Produção

Av. Prof. Almeida Prado, 128 Tr.2 Biênio, CEP 05508-900 - São Paulo - SP

11-3091-5363 r. 454 - fjblau@usp.br

\author{
Marly Monteiro de Carvalho \\ Professora Associada \\ Escola Politécnica da Universidade de São Paulo \\ Departamento de Engenharia de Produção
}

Av. Prof. Almeida Prado, 128 Tr.2 Biênio, CEP 05508-900 - São Paulo - SP 
11-3091-5363 r. 303 - marlymc@usp.br

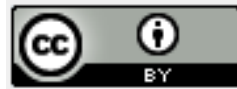

\title{
RESUMO
}

De maneira geral, os modelos de estratégia encontrados na literatura são predominantemente voltados para grandes empresas. Contudo, pequenas e médias empresas (PME) também necessitam de planejar suas estratégias, mas de maneira que sejam respeitadas suas peculiaridades. Neste contexto, este artigo apresenta um método simplificado para a formulação e o desdobramento da estratégia, voltado ao uso pelas PME. Este método foi desenvolvido através de uma série de estudos de casos, desenvolvidos em diferentes etapas, em pequenas empresas (10 a 500 empregados). A versão final deste método é uma estrutura de sete passos que considera tanto o ambiente empresarial e as competências essenciais da empresa. $\mathrm{O}$ resultado final almejado é o alinhamento da estratégia de negócio com a estratégia de manufatura. O método é aplicável para PME por ser simples e permitir economizar tanto o tempo como outros recursos escassos disponíveis para a formulação da estratégia, aspectos importantes neste tipo de empresa. Finalmente, apresenta-se um estudo de caso, no qual a versão final do método desenvolvido foi aplicada e analisada em uma pequena empresa brasileira.

Palavras-chave: Estratégia Competitiva, Estratégia para Pequenas Empresas, Estratégia de Manufatura.

\begin{abstract}
Strategy models found in the literature are usually more suitable for big companies. However, small and medium enterprises (SME) also need to plan their strategies, but in such a way that considers their peculiarities. In this context, this paper presents a simple method for strategy formulation and deployment in SME. This method was developed through a sequence of cases studies, developed in small companies (10 to 500 employees). The final version of this method is a seven-step framework that considers both business environment and firm core competencies. The final aim is the alignment of business and manufacturing strategies. This framework can be considered suitable for SME, since it is simple and allows saving time and scarce available resources for strategy formulation, both important issues in this kind of enterprises. Finally, a case study is presented, encompassing the analysis of the application of the final version of the method in a small Brazilian company.
\end{abstract}

Key-words: Competitive Strategy, Small Business Strategy, Manufacturing Strategy.

\section{INTRODUÇÃO}


De maneira geral, os modelos de estratégia disponíveis nas literaturas de negócios e na acadêmica são predominantemente focados em grandes empresas e corporações. Há também uma opinião estabelecida de que as pequenas empresas não seguem uma estratégia formal. As razões para este cenário são a complexidade da maioria das técnicas usadas no planejamento estratégico, a quantidade de investimentos financeiros exigidos para sua utilização e o conhecimento requerido para sua implementação. Por outro lado, Goy e Paturel (2004) indicam que esse debate já existe há muito tempo e que ainda não está concluído. Da mesma forma, Stonehouse e Pemberton (2002), estudando a aplicação de ferramentas pra elaboração de estratégia no Reino Unido, afirmam que há pouca evidência do uso de 'ferramentas' de análise estratégica, sendo mais comum o relato do uso de ferramentas destinadas às análises financeiras.

Estes fatores tenderiam a afastar as pequenas empresas da utilização de modelos voltados às suas estratégias de negócios. Ou como afirmam Stonehouse e Pemberton (2002), as grandes empresas usam intensivamente planejamentos de longo prazo e ferramentas de análise estratégica, enquanto que as empresas menores geralmente têm foco no curto prazo, fazendo o uso de políticas ao invés de planos formais. Stonehouse e Pemberton (2002) concluem ainda que há falta de pensamento estratégico nas empresas.

De acordo com Mintzberg (1994), o pensamento estratégico deve ser sintético, envolvendo tanto a intuição como a criatividade. Da mesma maneira, Mintzberg (1987) discute que a formulação da estratégia é ainda uma atividade artesanal. Entretanto, isto não significa que nenhum método seria necessário. Significa somente que o método não deveria ser idêntico para todas as situações. As grandes corporações podem aceitar a aplicação de um método mais complexo, mas em pequenas empresas o método deveria necessariamente ser mais simples.

Neste presente artigo, a formulação e a desdobramento da estratégia são discutidos no ambiente de pequenas empresas brasileiras, onde é necessária uma abordagem mais simples, mais barata e mais rápida. O artigo tem como objetivo analisar esta situação e apresentar diferentes maneiras para a melhoria da estratégia de negócio em pequenas empresas.

A fim de investigar o processo de formulação da estratégia em pequenas empresas, adotou-se a abordagem de estudo de casos. Inicialmente, um primeiro método de sete passos foi desenvolvido com base em trabalhos anteriores e avaliado em pequenas empresas brasileiras. Cada uma das etapas foi desenvolvida na forma de um brainstorming estruturado 
envolvendo os principais executivos e gerentes, visando manter o foco na estratégia de negócio.

Em conseqüência de uma primeira avaliação do método, um segundo método de sete passos foi desenvolvido e aplicado em pequenas empresas brasileiras para avaliar a adequação deste método revisado. Esta estrutura final foi considerada apropriada para pequenas empresas (aqui consideradas como aquelas com 10 a 500 trabalhadores), pois permite economizar tempo e recursos escassos para a formulação da estratégia, aspectos considerados importantes neste tipo de empresa.

\section{FUNDAMENTOS TEÓRICOS}

Este item descreve os principais conceitos teóricos que serão utilizados no conjunto de passos que serão detalhados no item 4.

\section{A necessidade de transformar estratégia em ações}

A elaboração da estratégia tem como objetivo a tomada de ação coerente com as ameaças e oportunidades oferecidas pelo ambiente. Da mesma forma, qualquer ação da empresa deve ser consequiência direta ou indireta da estratégia. Assim, não é suficiente definir uma estratégia . Segundo Porter (1985), o fracasso de muitas empresas deve-se à falta de capacidade de desdobrar uma estratégia competitiva geral em etapas de ação específicas necessárias para se obter vantagem competitiva.

Assim, este trabalho parte do princípio que existe um ambiente que deve ser entendido para se elaborar uma estratégia. Neste sentido, percepções diferentes do ambiente levam a estratégias diferenciadas. O processo de estratégia é um processo dialético, sintético e contínuo entre o ambiente e a empresa. Não existem princípios gerais ou fixos para a estratégia nem regras estabelecidas para um melhor desempenho. O que se busca, na elaboração da estratégia, é a adequação das competências da empresa ao ambiente onde ela está inserida de forma a que a empresa seja mais competitiva perante seus concorrentes (CARVALHO; LAURINDO, 2007).

Uma cautela que deve ser tomada nessa forma de entender a estratégia é que, se houver uma visão apenas parcial do ambiente, pode-se chegar a estratégias infrutíferas. Outra 


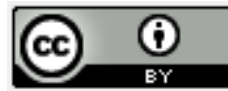

desvantagem é a dificuldade em transmitir este tipo de estratégia à empresa como um todo, dado seu caráter dialético e, portanto, muito mais sujeito à existência de conflitos.

Esta forma de se entender a estratégia se aproxima do conceito de Propósito de Ghoshal e Bartlett (2000). Neste conceito não é suficiente apenas rapidez, mas também que os resultados da ação sejam coerentes e flexíveis. Como diz Jack Welch, citado no livro de Slater (1999), que o processo (ou a arte) de gerenciamento e de liderança se reduz a uma questão muito simples, que seria determinar e enfrentar a realidade das pessoas, situações, produtos e atuar com objetividade e rapidez nessa realidade.

Desta forma, qualquer método desenvolvido a partir desta formulação deve prever uma descrição suficientemente abrangente do ambiente da empresa, um sistema de desdobramento que não leve em conta a hierarquia ou qualquer pressuposto sobre a estrutura da empresa, mas que considere uma forma de descrever as competências necessárias para a empresa.

Neste sentido, uma descrição bastante interessante do ambiente empresarial é dada por Porter (1985). É interessante, em primeiro lugar, o seu modelo de sistema de valores, no qual considera que o valor seria o que os compradores estão dispostos a pagar por aquilo que uma empresa lhes fornece a mais que seus concorrentes. A rentabilidade de uma empresa somente existiria se o valor que ela disponibiliza ultrapassa os custos envolvidos.

O sucesso empresarial, portanto, não adviria nem do respeito férreo à estrutura nem de fórmulas pré-concebidas de conduzir um negócio.

Ao valorizar a estrutura, algumas ferramentas, em verdade, burocratizam a elaboração de estratégias a simples "desdobramentos" ou "planos" que devem ser seguidos por todos os funcionários. Assim, muitas vezes se acredita em "gurus" que ditam regras administrativas dogmáticas que, não raramente, parecem carecer de uma fundamentação científica adequada. Assim, em geral, os planejamentos estratégicos tornam-se documentos formais gigantescos com pouca ou nenhuma utilidade prática, porém amplamente racionais.

O desdobramento deveria, pois, ser feito mais pela transmissão de conceitos do que pelo estabelecimento de documentos rígidos. Estes conceitos devem ser estabelecidos em linguagem simples de forma a serem entendidos por toda a empresa. Critérios de desempenho como os apresentados por Slack et al. (2000) e por Hill (1993) são interessantes para esta descrição. Segundo estes autores, a empresa precisa distinguir quais critérios são considerados pelos compradores, bem como qual a importância destes critérios na decisão de compra pelos seus clientes, Além disto, seria preciso avaliar realisticamente o desempenho da 
empresa nestes critérios em relação aos concorrentes, de forma a direcionar e priorizar seus esforços em prol de uma maior competitividade.

As competências podem ser descritas pelo que apresenta Zarifian (1999), conforme será visto mais adiante. Não se deve, porém se limitar às competências pessoais, mas também como as competências que podem ser consideradas como ativos da empresa.

\section{As características de uma boa estratégia para a pequena empresa}

A estratégia não é um conceito rígido baseado em regras ou paradigmas que levam a um único caminho para se obter melhoria e sobrevivência, para qual seria necessária a habilidade de seguir os novos paradigmas que forem surgindo. O que se procura estudar neste trabalho é que haveria múltiplos caminhos para a melhoria estratégica e que a escolha entre os diversos caminhos é um dos problemas principais da empresa.

Segundo Henderson (1989), os elementos básicos da competição estratégica seriam os seguintes:

1) Capacidade de compreender o comportamento competitivo como um sistema no qual competidores, clientes, dinheiro, pessoas e recursos interagem continuamente;

2) Capacidade de usar essa compreensão para predizer como um dado movimento estratégico vai alterar o equilíbrio competitivo;

3) Recursos que possam ser permanentemente investidos em novos usos mesmo se os benefícios conseqüentes só aparecerem a longo prazo;

4) Capacidade de prever riscos e lucros com exatidão e certeza suficientes para justificar o investimento correspondente;

5) Disposição de agir.

Assim, a estratégia é um processo onde se inicia pela análise (“compreensão") e atinge a ação. Mas a estratégia não se restringe a apenas a definir a ação. Esta ação deve ser rápida e é preciso que todas as pessoas da empresa compreendam a competição e que atuem de acordo com a estratégia. É preciso que haja unicidade na compreensão das estratégias dentro da empresa. Assim as missões e os objetivos devem estar claramente definidos. Ou seja, como cita Mcneilly (1999), os funcionários precisam conhecer a estratégia geral e sal 
missão entro dela de forma a que conheceçam sua intenção e seja capazes de porem em prática esta estratégia,. Analogamente, as diferentes divisões que compõem a empresa, bem como as funções dentro de cada uma destas divisões, precisam entender suas respectivas missões e como podem se apoiar umas às outras.

Como última característica, é importante ressaltar a necessidade da simplicidade. $\mathrm{Na}$ visão de Jack Welch, citado por Slater (1999), as pessoas sempre tendem a exagerar a complexidade dos negócios, cuja gestão na verdade seria uma atividade muito simples para aquele autor.

Desta forma, os planos muitos precisos seriam apenas disperdício de recursos quando o ambiente se torna cada vez mais turbulento e sem regras permanentes.

Assim, as características que deve ter uma boa estratégia seriam:

1) A análise adequada dos fatores influentes na estratégia (ambiente e competências);

2) A disposição para a ação de acordo com a estratégia;

3) A uniformização da estratégia através do conhecimento da estratégia por cada pessoa da empresa;

4) A rapidez das definições e das ações de acordo com a estratégia;

5) A simplicidade dos procedimentos e das informações.

Ao longo deste artigo, procurar-se-á investigar como o processo de formulação de estratégias em pequenas e médias empresas (PME) poderia atingir estas características acima listadas.

\section{Análise estrutural da posição da empresa}

A análise estrutural da posição competitiva da empresa parte do princípio que, segundo Porter (1985), a estratégia competitiva deveria surgir de uma compreensão aprofundada das regras da concorrência que determinam a atratividade de uma indústria (setor de atividades).

Estas regras da concorrência são os fatores externos à empresa que determinam limites às suas ações. Assim, estes fatores externos também influenciarão na forma com que cada empresa estabelecerá sua estratégia. Ainda segundo Porter (1985), as regras de concorrência baseiam-se na interação de cinco forças competitivas: a rivalidade entre os concorrentes existentes, a ameaça de entrada de novos concorrentes, a ameaça de produtos ou 
serviços substitutos, o poder de negociação dos compradores e o poder de negociação dos fornecedores.

De acordo com estudos anteriores (PIOVEZAN et al., 2003), percebeu-se a necessidade de detalhar um pouco mais as forças relacionadas ao poder dos fornecedores e ao poder dos clientes. Portanto, a força relacionada aos fornecedores tem como seus componentes mais importantes os fornecedores de materiais e de serviços e a mão-de-obra. $\mathrm{Na}$ força compradores foram analisados compradores e clientes finais.

A mão-de-obra foi destacada já que seu poder de negociação estaria ligado ao conhecimento e à sua disponibilidade, que se tornam cada vez mais importantes para a empresa, face ao aumento da importância do conhecimento para o sucesso das empresas. Da mesma forma, a força clientes finais foi enfatizada porque os requisitos destes clientes finais podem muitas vezes não serem traduzidos corretamente pelos compradores, inclusive podendo haver divergências. Assim, a análise destes fatores está destacada na Figura 1 e no Quadro 1.

\section{Estratégias genéricas e dimensões estratégicas}

Embora Porter (1985) tenha definido as estratégias genéricas como sendo estratégia de custos, de diferenciação e de enfoque, tal classificação das estratégias não permite visualizar o nível de detalhe necessário para os passos desenvolvidos nesse trabalho. Assim, detalhou-se a estratégia de diferenciação em estratégias de inovação em produtos e orientada a serviços para os clientes como, por exemplo, Fleury e Fleury (2000) adotam.

Por sua vez, o conceito de dimensões estratégicas pemite detalhar a estratégia genérica da empresas. Segundo Porter (1985), as dimensões estratégicas são: especialização; identificação de marcas; política de canal; seleção do canal; qualidade do produto; liderança tecnológica; integração vertical; posição de custo; atendimento; política de preço; alavancagem; relacionamento com a matriz; e relacionamento com os governos do país de origem e anfitriões. 


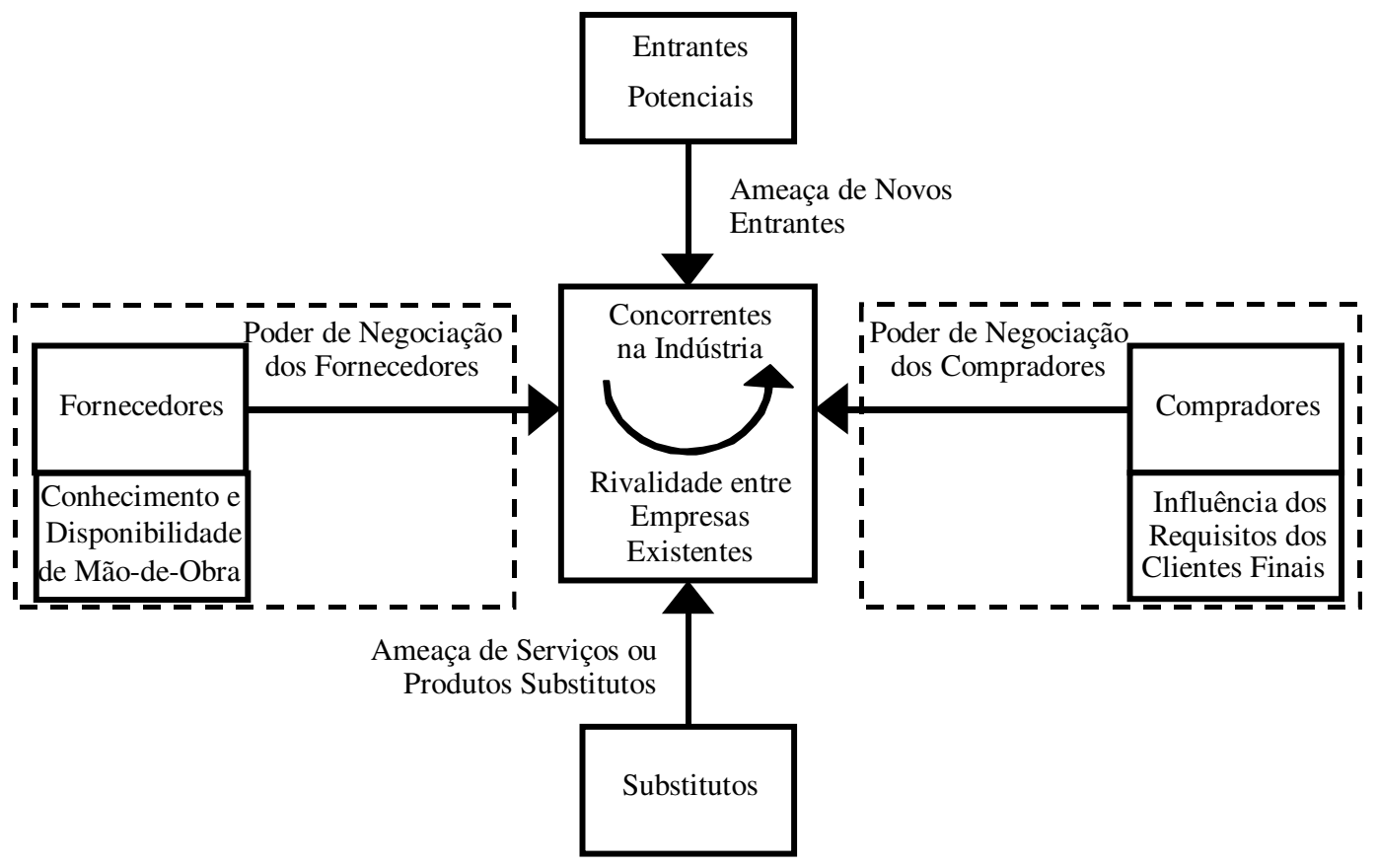

Figura 1: As forças competitivas (baseado em PORTER, 1990)

Quadro 1: Componentes das forças competitivas

\begin{tabular}{|l|l|}
\hline Força & Ação \\
\hline Compradores & $\begin{array}{l}\text { Poder de negociação e controle de preço } \\
\text { Influência dos requisitos dos clientes finais }\end{array}$ \\
\hline Fornecedores & $\begin{array}{l}\text { Poder dos fornecedores e controle do preço } \\
\text { Conhecimento e disponibilidade da mão-de-obra }\end{array}$ \\
\hline Concorrentes & Intensidade da rivalidade \\
\hline Substitutos & Ameaças de substituição \\
\hline Novos Entrantes & Barreiras de entrada \\
\hline
\end{tabular}

\section{Competências essenciais}




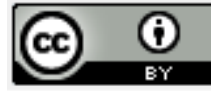

Segundo Prahalad e Hamel (1990), as competências essenciais seriam resultado do aprendizado coletivo na organização, especialmente como na coordenação das diversas habilidades de produção e na integração de múltiplas tecnologias.

Desse modo, é preciso identificar quais são as competências da empresa para estabelecer uma estratégia. Para reconhecer as competências essenciais, Prahalad e Hamel (1990) indicam que elas devem passar pelo crivo de três testes:

a) Uma competência essencial permite acesso potencial a uma grande variedade de mercados;

b) Uma competência essencial deve fazer uma contribuição significativa nos benefícios percebidos pelo cliente no produto final;

c) Uma competência essencial deve ser difícil de se imitar.

Apesar do uso comum do conceito de competências essenciais, tanto pesquisadores estudiosos da teoria da competência como os gerentes interessados em aplicar esta teoria têm freqüentemente encontrado dificuldades em definir conceitualmente competência e em identificar as reais competências da organização (SANCHEZ, 2004). O próprio Sanchez (2004), no entanto, indica que existem cinco modos de se abordar competências essenciais que se ligam às flexibilidades da organização. Um destes tipos, o tipo I, se refere às competências ligadas à flexibilidade estratégica, ou seja, à percepção das atividades que criam valor. Essa é o enfoque sobre a competência a que esse trabalho se refere.

Porém, há a necessidade de definir uma lista de competências essenciais. Adota-se, nesse sentido, os tipos de competências que Zarifian (1999) define. Segundo esse autor, as competências essenciais podem ser de cinco tipos: processos, técnicas, organização, serviço e sociais. A competência de processo está relacionada com a capacidade de estruturar os processos produtivos. A competência técnica está relacionada com a capacidade de realizar tecnicamente um produto ou serviço. A competência em organização está relacionada com a capacidade de distribuir recursos adequadamente. A competência em serviço está relacionada com a capacidade de estruturar os processos de serviço e de atendimento ao cliente. A competência social está relacionada com a capacidade da empresa em manter relacionamentos com governos, meio técnico, outras empresas ou a sociedade.

\section{Objetivos de desempenho}


Conceitos genéricos de estratégia são, em grande parte dos casos, pouco compreensíveis para o pessoal operacional, principalmente por não detalharem as ações necessárias. Assim, são necessários os objetivos de desempenho. Estes objetivos de desempenho são: qualidade, rapidez, confiabilidade, flexibilidade e custo (SLACK et al., 2000).

Slack et al. (2000) definem os objetivos de desempenho como:

a) Qualidade: fazer certo as coisas, mas as coisas que a produção precisa fazer certo variarão de acordo com o tipo de operação;

b) Rapidez: quanto tempo os consumidores precisam esperar para receber seus produtos e serviços;

c) Confiabilidade: fazer as coisas em tempo para os consumidores receberem seus bens ou serviços quando foram prometidos;

d) Flexibilidade: ser capaz de mudar a operação de alguma forma;

e) Custo: o dinheiro gasto na produção, principalmente pessoal, instalações, tecnologia, equipamentos e materiais.

Segundo Hill (1993), os objetivos competitivos podem ser ganhadores de pedidos, os qualificadores e pouco relevantes. Como esses cinco objetivos nem sempre têm trade off positivo, é fundamental que a organização tenha claro quais são seus critérios ganhadores de pedidos, verificando seu alinhamento à estratégia genérica (CARVALHO; LAURINDO, 2007).

\section{ASPECTOS METODOLÓGICOS}

O método proposto neste artigo resultou de uma evolução baseada em uma série de estudos de caso para analisar um método anterior para a formulação e o desdobramento da estratégia. A fim de investigar o processo da formulação da estratégia na pequena empresa, um primeiro trabalho foi desenvolvido em pequenas empresas brasileiras (PIOVEZAN; CARPINETTI, 1997). A base teórica usada foi baseada nos métodos do diagnóstico que apontam melhorias de qualidade operacionais (PIOVEZAN; CARPINETTI, 1999). 


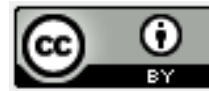

Os resultados do estudo foram analisados criticamente e uma nova estrutura teórica foi adotada, uma vez que a abordagem inicial diagnosticou a empresa com perspectivas préestabelecidas e não considerou as características específicas do mercado da empresa. Esta nova proposta foi desenvolvida baseada na pesquisa precedente e em ferramentas como o QFD - Desdobramento da Função Qualidade (AKAO, 1990). Incorporou também os conceitos de estratégia de negócio (PORTER, 1985) e os conceitos da estratégia de manufatura (SKINNER, 1969 e SLACK et al., 2000). Esta nova abordagem abrange três ramos de análise. O primeiro considera os processos internos da empresa, o segundo avalia a situação atual do ambiente empresarial e o terceiro trata da definição das estratégias do negócio e de manufatura (PIOVEZAN, 2000).

Para investigar as dificuldades desta proposta e visando aperfeiçoá-la, um segundo conjunto de estudos de caso baseados nesta nova abordagem foi executado em oito pequenas empresas brasileiras. Os resultados deste segundo conjunto de estudos de caso permitiram analisar a adequação desta nova estrutura para a identificação dos problemas e para ações de orientação para a melhoria da eficiência. A estrutura foi considerada praticável e os gerentes da empresa eram completamente receptivos para sua utilização.

Entretanto, o tempo para a aplicação desta estrutura foi considerado demasiado longo, pois a duração das reuniões em cada empresa foi de aproximadamente sete horas. A aplicação de um questionário de avaliação permitiu perceber outros problemas; especialmente que alguns conceitos eram difíceis de serem compreendidos.

Assim, uma terceira estrutura foi desenvolvida e se baseou em uma nova pesquisa bibliográfica que conduziu à incorporação de aspectos novos (PIOVEZAN et al., 2003). A simplificação e o esclarecimento de alguns conceitos eram alguns dos objetivos deste desenvolvimento. Conseqüentemente, nesta nova estrutura foram introduzidos os conceitos de competência, como indicados por Prahalad e Hamel (1990) e por Zarifian (1999). Uma análise inicial foi apresentada e o presente artigo apresenta a versão final do método apresentada neste trabalho.

Para verificar a aplicabilidade dos passos propostos no método atual, estes passos foram objeto de análise em mais um estudo de caso único (YIN, 2001). Este estudo de caso ocorreu em uma pequena empresa, onde os passos do método (descritos mais adiante) foram seguidos para se determinar pontos fortes e oportunidades de melhoria neste método.

A empresa foi escolhida de acordo com alguns critérios:

a) Tamanho da empresa: foi escolhida uma empresa de pequeno ou médio porte. 
b) Setor de atividade da empresa: foi escolhida uma empresa da cadeia produtiva da Construção Civil, na qual há avidez por melhoria de processos de gestão.

c) Tipo da empresa: a empresa escolhida tem a produção organizada e a liderança formalmente definida.

\section{PROPOSTA DE ESTRUTURA DE FORMULAÇÃO E DESDOBRAMENTO}

A proposta de um método para a definição estratégica de uma empresa é composta por sete passos principais encadeados de acordo com a figura 2. Estes passos, porém, não são estanques, ou seja, de acordo com o desenvolvimento de um passo, pode haver necessidade de retornar aos passos anteriores.

Este esquema indica que a estratégia é a combinação de uma análise do ambiente com as competências da empresa. Define-se empresa, neste item, como uma entidade que atua em determinado mercado. Existem empresas, na realidade, que atuam em vários mercados com produtos iguais ou diferentes.

No caso de empresas atuando em vários mercados com produtos iguais, cada mercado pode ser estudado separadamente como se fossem empresas diferentes. No caso de empresas atuando em um ou mais mercados com produtos diferentes, cada produto - ou família de produto - pode ser estudado como uma empresa diferente. Isto ocorre exceto quando forem produtos que disputem o mesmo mercado. Não há necessidade desta separação ser definida no início dos passos. Durante a execução, se ela for necessária, aparecerá como conseqüência da dificuldade das análises.

Os participantes desta definição devem ser limitados a seis ou sete pessoas em função das dinâmicas a serem realizadas (por exemplo, por brainstorming). A escolha dos participantes deve recair sobre os considerados líderes da empresa. Estes líderes não necessariamente precisam possuir alguma posição hierárquica na empresa, mas devem ser as pessoas que ajudam na tomada de decisões ou na divulgação de posições da empresa. 


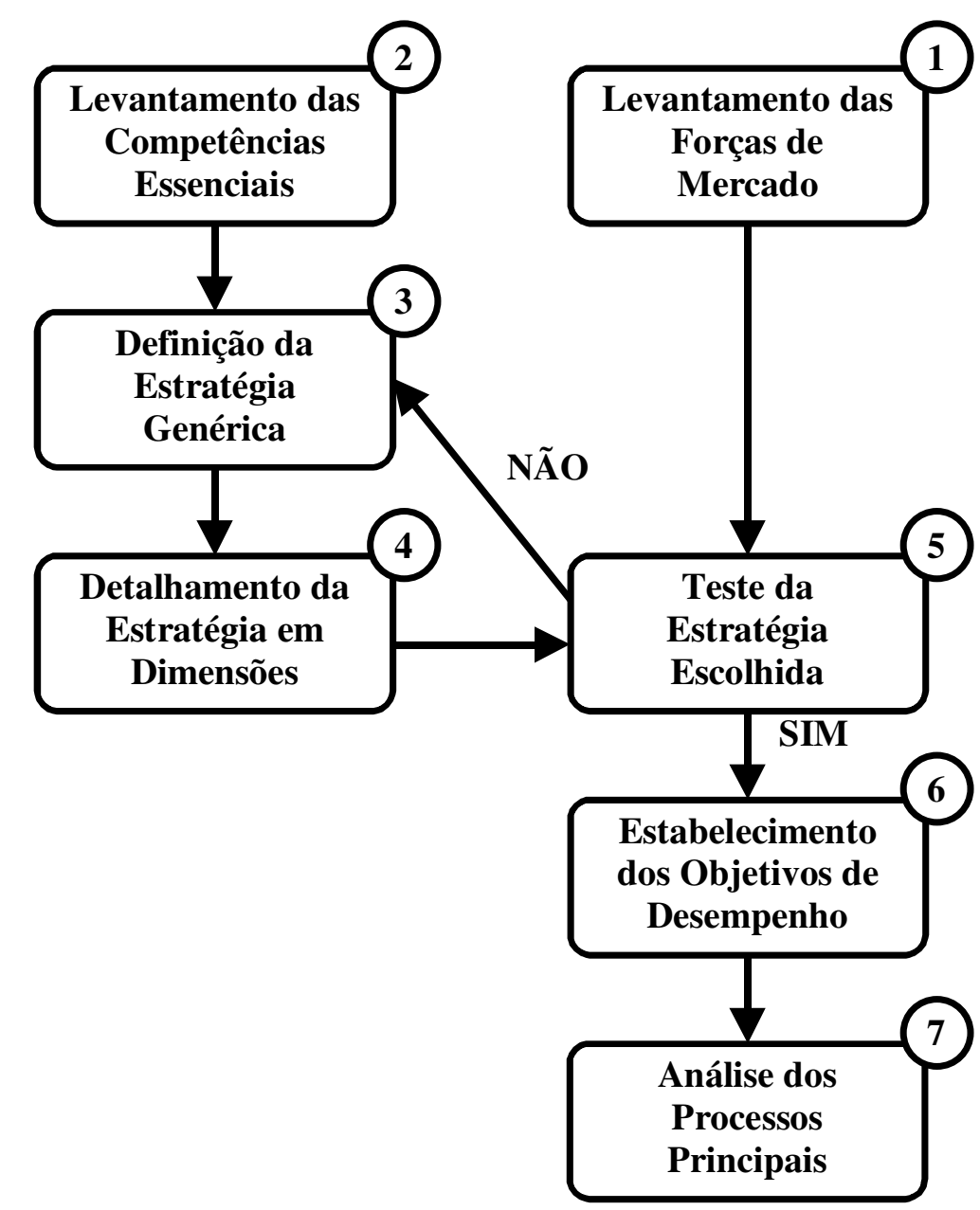

Figura 2: Passos para a elaboração da estratégia segundo o método proposto pelos autores deste trabalho

\section{Análise estrutural da posição da empresa}

Este passo é uma fase exploratória da empresa e do ambiente. O objetivo deste passo é a descrição das forças competitivas que determinam a ação da empresa. As forças competitivas foram detalhadas no item 2.3. Uma maneira de realizar esta fase é através de um brainstorming com os líderes da empresa, embora a experiência no setor (e a eventuial disponibilidade de dados setoriais) possa ajudar a empresa a direcionar sua visão. O produto desta fase é uma compreensão do ambiente no qual a empresa está inserida, ou seja, das regras de competição que estão em vigor para a empresa. É interessante notar que este 


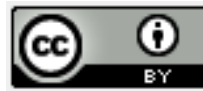

ambiente não é imutável. Uma matriz de frases descrevendo cada força competitiva é o resultado deste passo.

\section{Levantamento das competências essenciais}

O objetivo deste passo é a identificação das competências essenciais da empresa através dos testes propostos por Prahalad e Hamel (1990) para a identificação das competências essenciais da empresa. Este teste é feito sobre as possíveis competências essenciais definidas por Zarifian (1999), descritas no item 2.5. Utiliza-se o quadro ilustrado na figura 3 para este passo.

\begin{tabular}{|c|c|c|c|c|}
\cline { 2 - 5 } \multicolumn{1}{l|}{} & $\begin{array}{c}\text { Permite acesso a } \\
\text { vários mercados? }\end{array}$ & $\begin{array}{c}\text { Cliente percebe } \\
\text { os benefícios? }\end{array}$ & $\begin{array}{c}\text { Dificuldade de } \\
\text { imitar? }\end{array}$ & Soma \\
\hline Processos & & & & \\
\hline Técnicas & & & & \\
\hline Organização & & & & \\
\hline Serviço & & & & \\
\hline Sociais & & & \\
\\
Critérios: \\
1 - Pouco importante \\
2-Medianamente importante \\
3-Muito importante
\end{tabular}

Figura 3: Levantamento das competências essenciais

O critério a ser utilizado é da importância da competência da empresa no atendimento aos três testes propostos por Prahalad e Hamel (1990). Assim, para cada competência, são feitas as três perguntas que devem ser respondidas em função da importância da competência existente na empresa. As duas ou três maiores somas simples das linhas permitem a definição das duas ou três competências essenciais da empresa. Uma análise deve ser feita com os participantes para a confirmação destas competências essenciais.

\section{Definição da estratégia genérica}




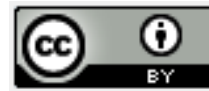

As duas ou três competências essenciais levantadas no item 4.2 são analisadas em sua capacidade de contribuição para a estratégia genérica (ver item 2.3). Para isso, utiliza-se o quadro ilustrado na figura 4. A soma dos pontos de cada estratégia é realizada e é, assim, definida a estratégia genérica a ser adotada.

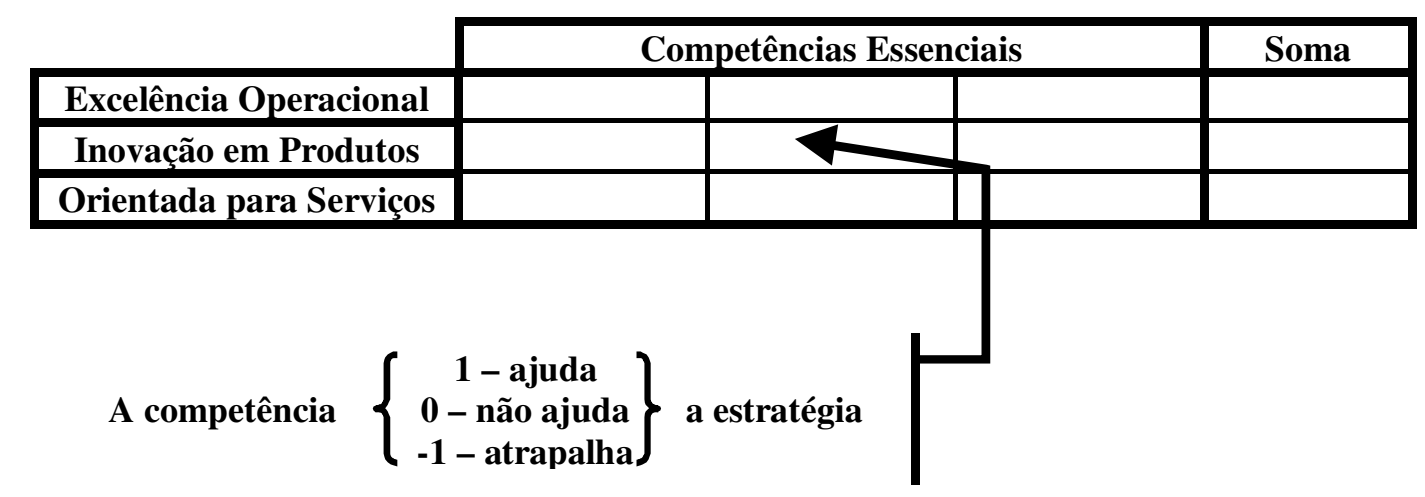

Figura 4: Definição da estratégia genérica

\section{Detalhamento da estratégia em dimensões}

Neste passo, utiliza-se o conceito de dimensões estratégicas (ver item 2.4) para detalhar a estratégia genérica definida em 4.3. A partir da lista das dimensões estratégicas, perguntam-se quais das dimensões são mais importantes para estratégia escolhida. São selecionadas, no máximo, três dimensões mais destacadas. Essa escolha visa descrever a estratégia de forma mais detalhada, indicando as formas de operacionalização da estratégia mais importantes.

\section{Teste da estratégia escolhida}

O produto dos passos anteriores é uma estratégia adequada para a empresa. Porém, há a necessidade de se confirmar se esta estratégia é realmente a que deve ser utilizada pela empresa. Assim, as dimensões principais definidas em 4.4 são comparadas com as forças competitivas definidas em 4.1. Para isso, é utilizada a tabela ilustrada na figura 5.

A última coluna é a somatória de todas as anteriores. Caso a soma total seja maior que zero, a estratégia em questão poder ser considerada uma boa estratégia. Caso a soma seja menor que zero, a alternativa avaliada pode não ser uma boa estratégia. Há uma escolha 


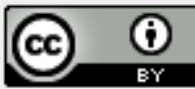

subjetiva neste passo. Neste ponto devem ser verificados se os riscos da estratégia são suficientemente conhecidos e se há a intenção de enfrentá-los.

\section{Estabelecimento dos objetivos de desempenho}

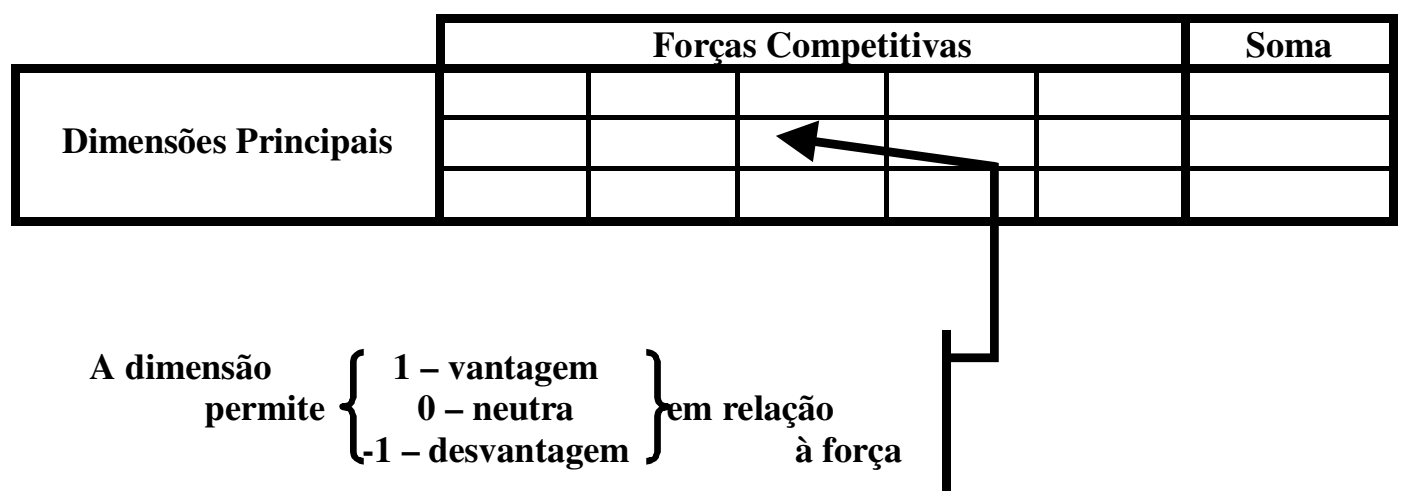

Figura 5: Teste da estratégia

O sexto passo tem como objetivo levar a estratégia definida no item 4.5 a uma forma mais compreensível para o pessoal operacional. Assim, a estratégia definida deve ser descrita mais detalhadamente em termos de objetivos de desempenho que servirão como critérios para a elaboração e implantação dos planos de melhoria definidos em 4.7.

A comparação das dimensões estratégicas escolhidas com os objetivos de desempenho (ver item 2.6) é realizada através de uma matriz como ilustra a figura 6. Para cada dimensão estratégica é estabelecida a força da relação entre ela e o objetivo de desempenho. Assim, esta matriz indica o que é estrategicamente desejável para a empresa. No preenchimento da matriz, cada um dos valores (1, 3 ou 9) só poderá ser repetido apenas uma vez para cada dimensão estratégica.

O objetivo desta fase é a priorização dos objetivos de desempenho em função da estratégia genérica da empresa. Esta priorização não é apenas fruto das necessidades e dos desejos dos clientes, mas sim de um posicionamento em função do ambiente no qual a empresa está inserida e os clientes fazem parte.

\section{Análise do alinhamento dos processos principais}




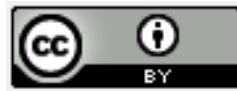

Neste passo, deve-se verificar se todos os processos da empresa estão coerentes com a estratégia. Assim sendo, cada processo é analisado em relação a seu atendimento aos objetivos de desempenho definidos. O resultado é uma matriz de acordo com a figura 7. A primeira coluna apresenta os principais processos de uma empresa como define Slack et al. (2000) e as próximas cinco são relativas à resposta à questão: o processo contribui ou não para o objetivo de desempenho?

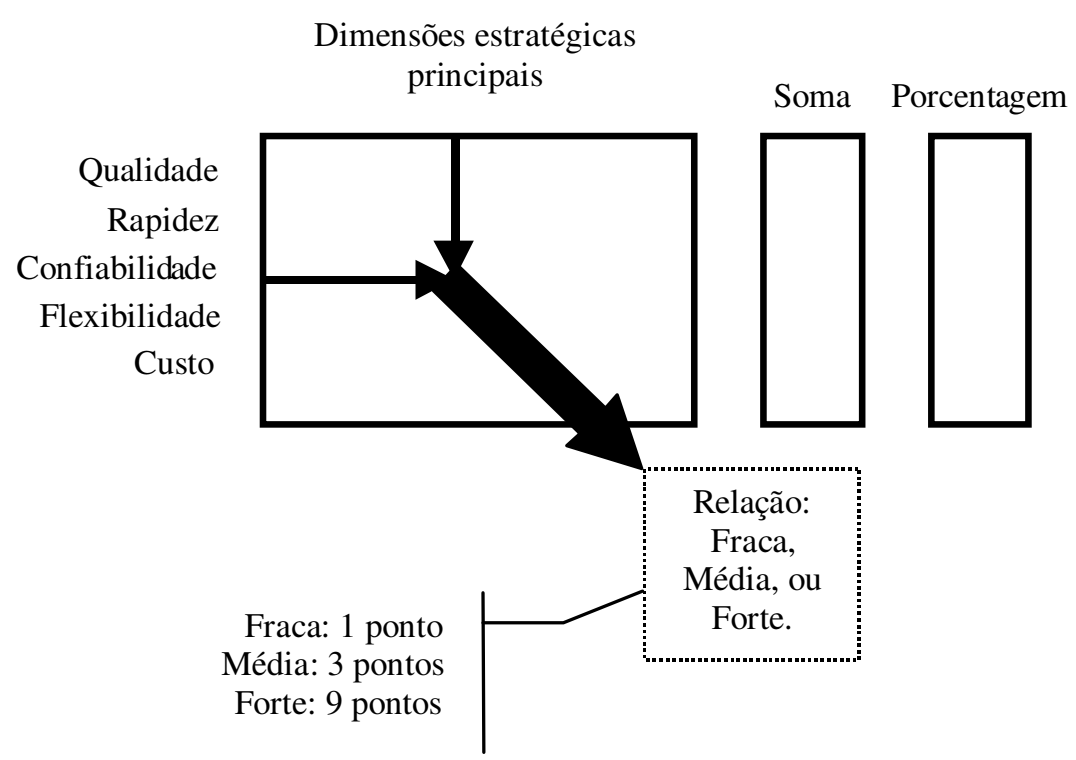

Figura 6: Matriz de desempenho estratégico

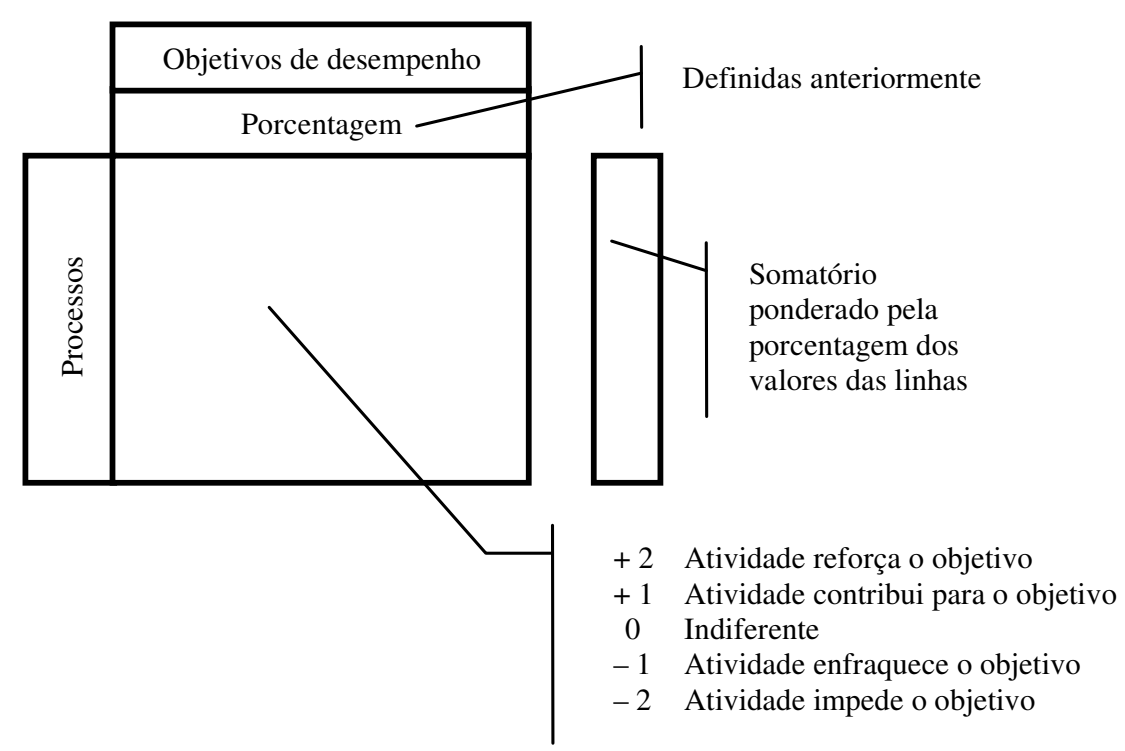

Figura 7: Análise dos processos da empresa em função dos objetivos de desempenho 


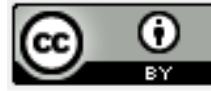

Os principais processos da empresa são: Produção; Engenharia e Suporte Técnico; Desenvolvimento de Produto ou Serviço; Recursos Humanos; Compras; Marketing; e Contabilidade e Finanças.

Este alinhamento é apenas a indicação dos processos que devem ser revistos para garantir o alinhamento das operações com a estratégia, e não um plano detalhado. $\mathrm{O}$ detalhamento desta estratégia em planos é uma atividade posterior. Os processos que devem ser revistos são aqueles com a soma mais negativa.

Mesmo que as somas de todos os processos sejam positivas, pode haver a escolha de algum processo que deve ser alterada visando a um maior alinhamento, principalmente entre os processos que obtiveram menor soma ponderada. $\mathrm{O}$ detalhamento dos planos é uma atividade posterior, pois o objetivo desta fase é apenas identificar quais processos devem ser modificados e em que sentido.

Nesta fase é importante verificar se o alinhamento dos processos realmente é executável e se há a intenção de realizar todas as mudanças estratégicas previstas. Havendo alguma negativa, é necessário rever, pelo menos, o passo anterior.

Um conjunto de indicadores de desempenho pode ser criado nesta fase para o acompanhamento da implantação da estratégia.

\section{A DEFINIÇÃO DA ESTRATÉGIA EM UMA EMPRESA}

A empresa onde o método foi aplicado atua no setor de construção civil, mas especificamente no ramo de instalações elétricas, incluindo projeto, execução e manutenção de instalações industriais e comerciais. A empresa atua principalmente na Baixada Santista. A direção da empresa é familiar e conta com um bom conceito no mercado, além de ter estrutura pequena e formalizada. Atualmente, a empresa conta com cerca de vinte funcionários e pode ser considerada uma pequena empresa. O trabalho foi conduzido com o sócio diretor da empresa durante 2005. A aplicação dos passos propostos está detalhada a seguir.

\section{Passo 1: Pesquisa da Estrutura de Mercado}


O quadro 2 indica as principais indicações sobre a estrutura de mercado apresentadas pela empresa. Nota-se que o mercado é considerado competitivo para a empresa, havendo principalmente problemas com a informalidade.

\section{Passo 2: Levantamento das competências centrais}

A aplicação do passo 2 levou à conclusão de que as principais competências se direcionam para as competências Técnicas, de Processos e de Organização. 
Quadro 2: Estrutura de Mercado da Empresa

\begin{tabular}{|c|c|}
\hline Força & Ação \\
\hline \multirow[t]{4}{*}{ Compradores } & Poder de negociação e controle de preço \\
\hline & $\begin{array}{l}\text { - } \text { Pressão de preços, principalmente ocorrendo leilões de preços. } \\
\text { - Informalidade nas relações comerciais } \\
\text { - } \\
\text { - } \\
\text { - Empreço aproximando-se do custo } \\
\text { Emaladas por baixo }\end{array}$ \\
\hline & Influência dos requisitos dos Clientes Finais \\
\hline & $\begin{array}{l}\text { - Problemas de corrosão e salitre notados após alguns anos } \\
\text { - Exigências de atendimento a normas técnicas pelos grandes usuários } \\
\text { - Poucas exigências pelos pequenos usuários } \\
\text { - Tendência de eliminar o intermediário }\end{array}$ \\
\hline \multirow[t]{4}{*}{ Fornecedores } & Poder dos fornecedores e controle do preço \\
\hline & $\begin{array}{l}\text { - } \text { Fornecedores vendem com preços maiores na Baixada } \\
\text { - Necessidade de realizar compras em São Paulo } \\
\text { - Necessidade de manter estoques maiores } \\
\text { - Poder de compra maior pela maturidade da empresa }\end{array}$ \\
\hline & Conhecimento e disponibilidade da Mão-de-Obra \\
\hline & $\begin{array}{l}\text { - Pouca disponibilidade de técnicos formados } \\
\text { - Necessidade de formação interna além da formação inicial técnica } \\
\text { - Necessidade de flexibilidade dos conhecimentos e das ações }\end{array}$ \\
\hline \multirow[t]{2}{*}{ Concorrentes } & Intensidade da rivalidade \\
\hline & $\begin{array}{l}\text { - Alta informalidade dos concorrentes } \\
\text { - Comportamento predatório } \\
\text { - Baixa associação entre concorrentes }\end{array}$ \\
\hline \multirow[t]{2}{*}{ Substitutos } & Ameaças de substituição \\
\hline & $\begin{array}{l}\text { - Não há grandes ameaças de substituição } \\
\text { - Grande evolução tecnológica de equipamentos }\end{array}$ \\
\hline \multirow{2}{*}{$\begin{array}{l}\text { Novos } \\
\text { Entrantes }\end{array}$} & Barreiras de entrada \\
\hline & $\begin{array}{l}\text { - Sem grandes barreiras de entrada } \\
\text { - Bairrismo de alguns clientes que evitam contratar empresas de São Paulo } \\
\text { pelo histórico de maus serviços por parte de algumas empresas que } \\
\text { tentaram entrar no mercado } \\
\text { - Necessidade de infra-estrutura mínima da empresa }\end{array}$ \\
\hline
\end{tabular}




\section{Passo 3: Desdobramento das competências em estratégia}

A aplicação do passo 3 indicou que a estratégia que empresa deve escolher é a excelência operacional.

\section{Passo 4: Desdobramento da estratégia em dimensões}

De acordo com o item 4.4, as dimensões principais escolhidas foram especialização, liderança tecnológica e política de preço.

\section{Passo 5: Teste da estratégia no ambiente competitivo}

O resultado positivo obtido no teste do passo 5, mostra que a estratégia escolhida tem boas possibilidades de ser adequada.

\section{Passo 6: Desdobramento das dimensões em critérios de desempenho}

A Tabela 6 indica que os principais critérios de desempenho da empresa devem ser direcionados para a Qualidade e a Flexibilidade. 
Quadro 3: Estabelecimento dos critérios de desempenho

\begin{tabular}{|c|c|c|c|c|c|}
\hline & 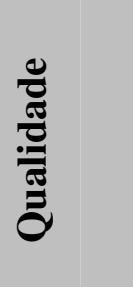 & 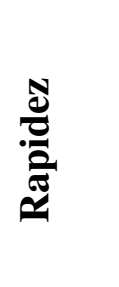 & 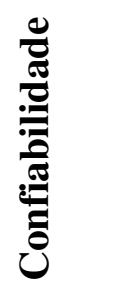 & 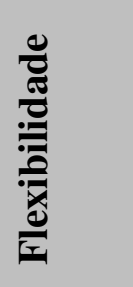 & 竘 \\
\hline Especialização & 9 & 3 & 9 & 3 & 1 \\
\hline Liderança Tecnológica & 9 & 3 & 3 & 9 & 1 \\
\hline Política de Preço & 1 & 1 & 3 & 9 & 9 \\
\hline Soma & 19 & 7 & 15 & 21 & 11 \\
\hline Porcentagem & $26,0 \%$ & $9,6 \%$ & $20,5 \%$ & $28,8 \%$ & $15,1 \%$ \\
\hline
\end{tabular}

\section{Passo 7: Análise da adequação dos processos principais}

A aplicação do passo 7 indicou que os processos Recursos Humanos, Engenharia e Suporte Técnico e Vendas são os que mais se distanciam da estratégia da empresa e são aqueles que devem sofrer interferências para a adequação.

\section{CONCLUSÕES}

Os objetivos do trabalho podem ser considerados alcançados na medida em que se conseguiu estudar o conjunto de passos em um caso, cujos resultados foram positivos, já que a receptividade pelos entrevistados na empresa foi boa. Porém, um único estudo de caso não é conclusivo quanto à validade geral do método e mais casos devem ser desenvolvidos para essa validação. Esses estudos também devem verificar se, a longo prazo, o método produz resultados adequados para a empresa.

Como aspectos positivos do método, pode-se afirmar que o conjunto de passos permitiu que a estratégia da empresa fosse mais bem compreendida pelos participantes e que a determinação de programas de melhoria pudesse ser mais bem definida. Esse é um importante avanço em direção à utilização de processos de formulação de estratégia mais complexos que envolvam, por exemplo, o levantamento de dados sistemático sobre o ambiente. 


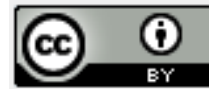

Da mesma forma, o conjunto de passos propostos auxilia na comunicação da visão no sentido de conferir simplicidade (principalmente quando se compara este conjunto de passos com o planejamento estratégico), permitir que seja utilizada em fóruns diferentes (por exemplo, em reuniões em partes da empresa), além de evitar e explicar inconsistências aparentes.

A viabilidade de aplicação deste conjunto de passos permite fazer a proposição de que existe a possibilidade de serem estabelecidas melhorias com rapidez em pequenas e médias empresas a partir da análise racional de seu ambiente e de sua estrutura.

Por outro lado, como ponto negativo, o conjunto de passos apresentado pode conduzir rapidamente a uma estratégia, mas não apresenta nada que garanta que a estratégia escolhida é a melhor para um determinado ambiente competitivo, principalmente por basearse apenas na visão de poucas pessoas da empresa. Assim sendo, não há a garantia do sucesso da estratégia, mas apenas a indicação, de maneira mais sistemática, de um caminho a seguir. Para corrigir essa deficiência, o método pode ser uma primeira iniciativa na aplicação de conceitos estratégicos na empresa, mas análises mais consistentes devem ser feitas quando esses conceitos forem aprofundados.

Uma das razões desta falha é que o conjunto de passos utiliza uma base de dados sobre o ambiente competitivo que pode ser considerada fraca em muitos casos: a experiência dos diretores e líderes da empresa. Assim, podem surgir estratégias baseadas em premissas fracas que resultem em insucesso. Assim, para melhorar o processo, seriam necessárias informações mais confiáveis sobre a indústria na qual a empresa atue, tal como bases de dados setoriais.

Outro fator que pode impedir a aplicação com sucesso do conjunto de passos é o surgimento de conflitos de idéias entre os participantes. $\mathrm{O}$ aplicador do método proposto deve estar atento, pois o conjunto de passos não tem estrutura para intermediar conflitos inconciliáveis. Por outro lado, podem surgir pessoas que, por carisma ou posição hierárquica, dominem a reunião, impondo idéias. Novamente o aplicador deve estar atento e evitar que esta atitude faça surgir ume estratégia sem consenso, mas por imposição.

Um último fator que impede a aplicação com sucesso é a dificuldade que empresários e gerentes têm de explicitar a estratégia da empresa. Em geral, tal dificuldade não está ligada à capacidade do empresário ou gerente, mas no temor de que, definindo e explicitando a estratégia, ela possa ser apropriada e, conseqüentemente, copiada por um concorrente. 
Quando, porém, estes problemas são levados em conta, este conjunto de passos pode ser útil para a compreensão dos mecanismos do mercado competitivo onde uma determinada empresa está inserida e para a definição clara dos caminhos a seguir. É uma forma racional porém simples - de indicar uma direção que seja seguida de forma coesa e coerente por todas as pessoas ligadas à empresa.

O conjunto de passos também atende aos objetivos definidos no item 2.3 como as características de uma boa estratégia, pois é rápido, simples e utiliza todas as variáveis intervenientes na empresa. Este conjunto de passos permite uma divulgação para empresa por sua simplicidade e pelo fato de traduzir a estratégia da empresa em objetivos de desempenho simples. Isto faz com que toda a empresa tenha condições de agir de acordo com a estratégia definida. O simples fato de conduzir os gestores a pensarem, de forma organizada e com linguagem uniformizada, nas questões relativas à definição do negócio da empresa, já é uma contribuição importante.

Futuros estudos poderão ampliar a discussão e aprofundar o questionamento sobre o método proposto e suas dificuldades acima apontadas.

\section{REFERÊNCIAS}

AKAO, Y. Quality Function Deployment: Integrating Customer Requirements into Product Design. Cambridge (MA), Productivity Press, 1990.

CARVALHO, M.M; LAURINDO, F.J.B. Estratégia Competitiva: dos conceitos à implementação. São Paulo, Atlas, 2007.

.FLEURY, M.T.L.; FLEURY, A.C.C. Estratégias Empresariais e Formação de Competências. São Paulo, Atlas, 2000.

GHOSHAL, S.; BARTLETT, A.C. A organização individualizada: as melhores empresas são definidas por propósitos, processos e pessoas. Rio de Janeiro, Campus, 2000.

GOY, H.; PATUREL, R. Les problématiques de diagnostic et de projection dans les PMI. Revue Française de Gestion; v. 30, n.150, May/Jun 2004. 


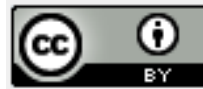

HENDERSON, B.D. The Origin of Strategy. Harvard Business Review, nov-dez., 1989.

HILL, T. Manufacturing Strategy. 2nd ed., Macmillan, 1993.

MCNEILly, M. Sun Tzu e a arte dos negócios. Rio de Janeiro, Campus. São Paulo, Publifolha, 1999.

MINTZBERG, H.; WATERS, J. Of strategies, deliberate and emergent. Strategic Management Journal, vol. 6, 1985.

MINTZBERG, H. Crafting Strategies, Harvard Business Review, jul-aug., 1987.

MINTZBERG, H. The fall and rise of strategic planning, Harvard Business Review, jan-feb., 1994.

PIOVEZAN, L.H.; CARPINETTI, L.C.R. Diagnóstico da Qualidade em Micro e Pequena Empresa: Estudo de Casos. ABEPRO, XVII ENEGEP - Encontro Nacional de Engenharia de Produção, Gramado, Brasil, 1997.

PIOVEZAN, L.H.; CARPINETTI, L.C.R. Estratégia empresarial e de manufatura: considerando sua importância na implantação de melhorias. Universidade Regional de Blumenal, Revista de Negócios, v.4, p. 55-63, 1999.

PIOVEZAN, L.H. Desdobramento da estratégia: integrando empresa e ambiente competitivo. São Carlos, EESC - USP, 2000. Dissertação de Mestrado.

PIOVEZAN, L.H., LAURINDO, F.J.B.; CARVALHO, M.M. Formulation and Deployment of Strategy: an approach for Small Business. Euroma Poms Joint International Conference, Cernobbio, Italy, 2003. 


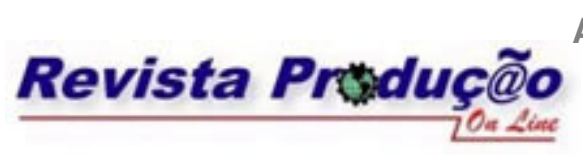

PORTER, M.E. Competitive Advantage: Creating and Sustaining Superior Performance, The Free Press, 1985.

PRAHALAD, C.K.; HAMEL, G. The Core Competence of the Corporation. Harvard Business Review, mai-jun., 1990.

SANCHEZ, R. Understanding competence-based management: Identifying and managing five modes of competence. Journal of Business Research, n.57, 2004.

SKINNER, W. Manufacturing: missing link in corporate strategy, Harvard Business Review, may-jun., 1969.

SLACK, N., CHAMBERS, S.; JOHNSTON, R. Operations Management. 3rd ed, Prentice Hall, 2000.

SLATER, R. Liderança de alto impacto. Rio de Janeiro, Campus. S. Paulo, Publifolha, 1999.

STONEHOUSE G.; PEMBERTON J. Strategic planning in SMEs - some empirical findings. Management Decision; v. 40, n.9, 2002.

YIN, R. Estudo de caso: planejamento e métodos. Porto Alegre: Bookman, 2001.

ZARIFIAN, P. Objectif Compétence, Éditions Liaisons, 1999. 